INTERNATIONAL DESIGN CONFERENCE - DESIGN 2018

https://doi.org/10.21278/idc.2018.0455

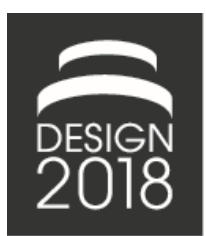

\title{
THE APPRAISAL OF SUSTAINABLE MATERIALS
}

\author{
F. I. Bahrudin and M. Aurisicchio
}

\begin{abstract}
This paper seeks to understand how users appraise sustainable materials. Using think-aloud sessions, appraisals of sustainable materials embodied in products were collected from users and categorised. To account for the appraisal of aspects such as origin, use and end of life of materials, we have extended a previous categorisation of material appraisals to include a systemic theme. The results stress the importance of the sensorial and semantic themes and the existence of relationships between appraisal themes. This understanding is useful to facilitate the uptake of sustainable materials.
\end{abstract}

Keywords: sustainable design, user experience, multisensory product experience

\section{Introduction}

Over recent years, a shift is occurring in manufacturing from traditional to sustainable materials. This shift is critical to reduce the use of declining finite natural resources and pursue a more sustainable development pathway as proposed in the Brundtland Commission's report 'Our Common Future' (WCED, 1987). Despite a constant and dynamic growth, the development of sustainable materials is still in its infancy (Bahrudin et al., 2016). Sustainable materials are receiving more attention in product development aided by the diffusion of concepts such as material detoxification (Van Weenen, 1995) and dematerialisation, i.e. the substitution of virgin materials with recycled material (Fiksel, 2006), and the replacement of resource intensive materials with sustainably harvested and renewable materials (OECD, 2010). The development of the field is driven by industrial efforts as much as the democratisation of knowledge and production technologies (Mota, 2011), which have spurred the exploration of multiple DIY materials (Rognoli et al., 2015). Various types of renewable virgin materials as well as by-product and second-life waste materials have been converted into products such as household objects, packaging, furniture, clothing and accessories, and building materials. While products made of recycled plastic and biodegradable plastic are often indistinguishable from traditional materials, new unconventional materials have entered the market. For instance, a luxury brand has started marketing sunglasses made of liquid-wood (Ho, 2014) and an outdoor clothing company has produced jackets made of bacterial based material (Bahrudin et al., 2016). These materials often have unique sensorial qualities. The brands marketing these products seem to make a strategic use of the biography of the materials both to position themselves, as well as to accentuate their environmental concerns. Labels, marks, leaflets and websites are examples of touch-points used to communicate sustainable credentials and to make users aware of what they purchase, connecting them to the intangible values of materials. A critical issue in this context is that little is known about how users appraise and perceive sustainable materials and how additional information provided to users influence their appraisals and perceptions.

This research aims at determining the ways in which sustainable materials are appraised. Specifically, the research examines the following question: How are sustainable materials appraised? In the research ten participants were exposed to products embodying sustainable materials, informed of the material origin, and asked to appraise the materials. 
By understanding the appraisal of sustainable materials, we expect to be able to provide designers with more instruments to shape positive perception towards sustainable materials leading to increased acceptance. This is important to shorten the gestation period of new sustainable materials prior to their commercial success.

\section{Literature review}

\subsection{Material experience}

The process by which users experience a product is influenced by multifaceted and intertwined factors, not just the absolute attributes or utilities of the product. User experience is a research field concerned with understanding all aspects of the interaction of the end user with a particular product, service or system (Carlos et al., 2011; Kremer et al., 2014). Among others, user experience investigates the affective responses to concrete and abstract product attributes (Bongard-blanchy and Bouchard, 2015). When engaging with a product, users typically infer and associate with its attributes to establish perception, and form evaluations and preferences.

The perceptual components of a product can be categorised into two types, namely aesthetic attributes and perceived attributes (Ashby and Johnson, 2003). The aesthetic attributes deal with sensorial properties of materials, which consist of visual, touch, sound, smell and taste. These sensorial properties trigger human senses and are processed as images forming the users' perception of products or services (Hultén, 2011). On the other hand, the perceived attributes refer to symbolic meanings. This meanings are triggered by practical, cognitive, symbolic, and hedonic values of products (Rodrigues et al., 2011). Researchers in the field of material and design have started investigating the role of materials in meaning creation. In particular, the interactions of users with materials can be seen as experiences, a concept similar to the aforementioned user experience. Karana (2009) in her research investigated how materials obtain their meanings and how materials interact with other product attributes in meaning creation. In the study, material appraisal items from a variety of publications and interviews were collected and categorised into seven descriptive categories based on their themes (see Table 1). Users recognise materials not only by assigning them to a specific category but also by estimating their quality, which sometime can be highly subjective and is detached from the objective utilities of the material (Fleming et al., 2013). For instance, dark, clear and glossy wood is evaluated as expensive, sophisticated, rare and interesting (Fujisaki et al., 2015), whereas a radial section of softwood evokes mellow, pleasing and natural feelings (Song and Zhao, 2011). In her research Karana found that when users appraise a material, typically there is a link between use and associative descriptions, and manufacturing process descriptions and sensorial descriptions.

Table 1. The appraisal descriptive categories and their definitions (Karana, 2009)

\begin{tabular}{|l|}
\hline Appraisal descriptive categories \\
\hline $\begin{array}{l}\text { Use description -refers to specific product or unique environment in which a } \\
\text { material is employed for a particular purpose. Eg: handle for organic form }\end{array}$ \\
\hline $\begin{array}{l}\text { Manufacturing process -expresses the applied production or treatment techniques } \\
\text { for the appraised product. E.g: glazed }\end{array}$ \\
\hline $\begin{array}{l}\text { Technical description -refers to quantifiable technical properties, which mostly } \\
\text { derived from the chemical structure of the material. Eg: strength }\end{array}$ \\
\hline $\begin{array}{l}\text { Sensorial description -making reference to interactions between materials and } \\
\text { users through the five senses, sight, touch, smell, taste and hearing. Eg: smooth }\end{array}$ \\
\hline $\begin{array}{l}\text { Emotional description -the subjective feelings of people towards a material, often } \\
\text { automatically and unconsciously. Eg: surprise }\end{array}$ \\
\hline $\begin{array}{l}\text { Associative description -association to another items or contexts that requires } \\
\text { retrieval from memory and past experience. Eg: cheese like }\end{array}$ \\
\hline $\begin{array}{l}\text { Expressive semantic description -the kinds of meanings we attribute to materials } \\
\text { after the initial sensorial input. Eg: modern }\end{array}$ \\
\hline
\end{tabular}


Further, four experiential levels of material experience were identified, namely sensorial, affective, interpretive and performative (Giaccardi and Karana, 2015). The sensorial level refers to the phases in which users' sensorial modalities, i.e. vision, touch, smell, sound and taste, are triggered. The affective level describes the emotions elicited by the quality of materials, inner thoughts and personal beliefs. The interpretive level concerns how users interpret and judge materials, that is the situated meanings ascribed to materials after the initial sensorial encounter. Finally, the performative level is about the performance that users obtain from a product. This level is significantly influenced by sensorial perceptions, ascribed meanings and emotions. In a nutshell, the sensorial experience relates directly to the aesthetic of materials, whereas the performative experience is about the way in which users interact with the performance of materials. The emotional experience refers to the feelings of users and finally the interpretive experience is defined by how users judge the meaning of material.

\subsection{Perception of sustainable materials}

The introduction phase of a new material can be a challenging time for a manufacturer. In this phase, the manufacturer aims at establishing a market, while the material faces public assessment for the first time. For example, during the time when plastic started to form its own image by putting forward its characteristics, it barely survived public repudiation. The unfamiliar intrinsic and extrinsic properties of plastics had led users to an emotional aversion or strong feeling of disgust. The novelty value of plastic was not appreciated (Suggit, 1997) and it had a long-lasting image of poor value and ephemeral pieces (Newport, 1997; Shashoua, 2008). Some people even felt apprehensive about the origin of plastic as they considered it coming from 'long complex derivative urine' or 'organic waste from the bowels of earth' and to some extent it was blamed for everything bad in America (Meikle, 1997). Japanese people were even found to be fearful and anxious of plastic's eternality (Cleminshaw, 1989).

Similar to the early plastic era, sustainable materials can evoke inferior impressions. For instance, it has been argued that biopolymers could follow the initial journey of plastics, which involved imitation and substitution (Manzini, 1989; Rognoli et al., 2011; Tonuk, 2016). It was also found that natural fibre composite materials, when used as surrogate materials, have a low esteem image and are often correlated to poverty, low-quality, unattractiveness and second-rate (Rognoli et al., 2011). In addition, it is known that products made of waste materials are perceived low quality by consumers (Biswas et al., 2000; Wang and Hazen, 2015). Overall it seems that at present the purchase of products made of recycled materials is more symbolic of good intentions and social responsibility than actually supporting sustainable design (Crabbe, 2012).

Perceived sustainability is critical for successful introduction of sustainable materials. It results from the dynamic interplay of many elements, e.g. preconceptions and world views (Wilkes, 2014). An element of interest to this research is the biography of the material including the substances that the material is made of, its life cycle and how much the material conform with specific criteria such as recyclability, biodegradability, and durability (Wilkes et al., 2016).

In a pre-study about willingness to purchase bio-based products, the resource basis or material origin was found as an important aspect that users would like to know about (Kainz, 2016). In another study, it was shown that users' confidence and satisfaction were increased by knowing the content of bio-based plastics in a product (Iwata, 2015) and items which are labelled or prompted to indicate that they have recycled content have shown a remarkable increase in purchase (McKenzie-Mohr, 2000). TYVEK, for example, had its premium product status enhanced by introducing post-consumer waste (i.e. milk bottle) into their material (Sharfman et al., 2001).

Information about the biography of a material, e.g. material proximity and origin, was found to make its sustainability claims more concrete and trigger higher pro-social experience (Magnier et al., 2017). Variation in the proximity and origin of materials embodied in products was tested in previous studies and it created discrepancies in user interest and preference (Yue et al., 2010; Kainz, 2016; Scherer et al., 2017). The material biography may also have an effect where the meaning of the original product is carried into the new product. For example, a jacket made from hot air balloon carries a 'freedom' feeling (Tseng Mu, 2013).

Despite the benefits of making the material biography known, it remains the design challenge of how to communicate. On one hand, product information has to be communicated concisely as users may 
be overwhelmed with the quantity of data (Mudgal et al., 2012) leading them to feel sceptical, particularly with partial and subjective ethical claims (Maheshwari and Malhotra, 2011; Hoek et al., 2013). As identified in previous research, users juggle between the perceived value and perceived risk (Wang and Hazen, 2015) and they believe that there is a trade-off between sustainability and its performance which often lead them to feelings of guilt and uncertainty (Luchs et al., 2010). On the other hand, formulating valuable sustainable visual cues is not a straight forward task and if not carefully pursued, the product image can be undesirable (Pedgley, 2014). For natural fibre, the fibreness, reflectiveness and roughness qualities should be designed efficiently as there is a major contradiction between 'natural' and 'high-quality' meaning (Karana and Nijkamp, 2014). Explicit trade-offs may also occur between sustainability and aesthetics (Luchs et al., 2012). The use of sustainable materials with 'green' aesthetic, for example, may emerge as an impediment to perceived quality (Petersen and Brockhaus, 2017). There are indeed challenges to market sustainable products that defy aesthetics and social conventions particularly in nowadays culture that valorise newness and perfection (Marchand, 2008).

Clearly, the market of sustainable products is challenging and the future is still uncertain. In addition, data on the perception towards sustainable materials are fragmented and present a predicament to material stakeholders. Capturing the perceptions or early reactions to these materials will provide material stakeholders with an understanding of how to better commercialise them.

\section{Methodology}

Six stimuli in the form of consumer products embodying sustainable materials were evaluated using 'think-aloud-interview' sessions with ten participants. Among the participants, four were females and six males. Two were chemical engineering students and eight design engineering students at Imperial College London. Each individual session took approximately thirty minutes. The verbal responses of participants were audio recorded and subsequently transcribed.

Given the number of stimuli investigated in this research and the fact that each participant was asked to assess them individually, 'think-aloud-interview' sessions were selected as they do not demand high cognitive load (Charters, 2003). These sessions can be conducted either concurrently (i.e. users report their evaluations, while interacting with products), or retrospectively (i.e. users recall their experiences with products) (Kuusela and Paul, 2000). The former technique was adopted to allow direct capture of the cognitive activities during material appraisal.

The stimuli were taken from a dataset of consumer products including renewable and recycled materials collected by Bahrudin et al. (2016) (see Table 2). The products selected for the study had to satisfy the following criteria:

- be commercially available consumer products;

- have conventional (product 1) or unconventional (products from 2 to 6 ) aesthetics;

- be made of either post-consumer waste such as recycled materials (products 1 and 2) and reused materials (products 3 and 4 ) or renewable materials (products 5 and 6 ).

Table 2. The six stimuli used in the interview sessions

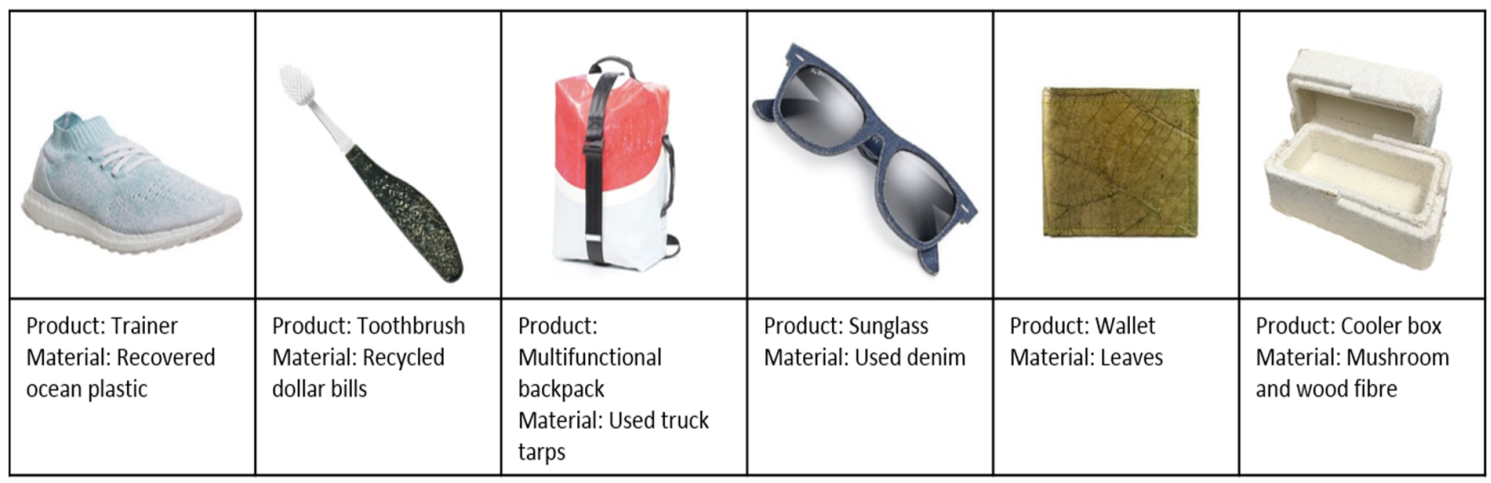


For the interview sessions the stimuli were clearly labelled stating the product type and their material origin, and were arranged randomly on a large table in a room with good lighting and minimum visual and noise distraction. The material origin was revealed to the participants to create an appraisal situation comparable to that increasingly experienced by consumers at the point of purchase of sustainable products. Prior to the interview, respondents were informed of the objective of the study. Respondents were asked to engage with a product at a time. While interacting with the products they were asked to verbalise their thoughts, feelings and opinions related to the materials.

A total of sixty appraisals were collected and transcribed. All responses were chucked into sentences and analysed to uncover individual appraisal themes. The appraisal themes were subsequently categorised using the categorisation proposed by Karana (2009).

\section{Results}

\subsection{Categorising the appraisals of sustainable materials}

All respondents expressed appraisals across the seven thematic categories used to code the data (see Figure 1). Table 3 shows examples of appraisal for each thematic category.

The 'use' evaluations were predominantly aimed at establishing the appropriateness of the materials in general and their specific properties in relation to the product applications.

The 'technical' evaluations focused predominantly on the verification of the performance of the materials. Many respondents used this thematic appraisal to express uncertainty on the functional integrity of the materials.

The 'sensorial' evaluations were centred on visual and tactile aspects of the materials. Colour, texture, hardness, softness and smoothness were the most appraised properties, whereas odour and sound were the least mentioned.

The 'emotional' evaluations were predominantly concerned with surprise. Most respondents clearly expressed their amazement as soon as they become familiar with the material origin.

The 'associative' evaluations were used by participants to recognise the materials assessed and consisted of recalling known and comparable materials and their sensorial properties.

The 'expressive semantic' evaluations focused primarily on making meaning from aesthetic, technical and use aspects of the product. Prior experience with the materials had an important role in these evaluations together with current assessment and speculations.

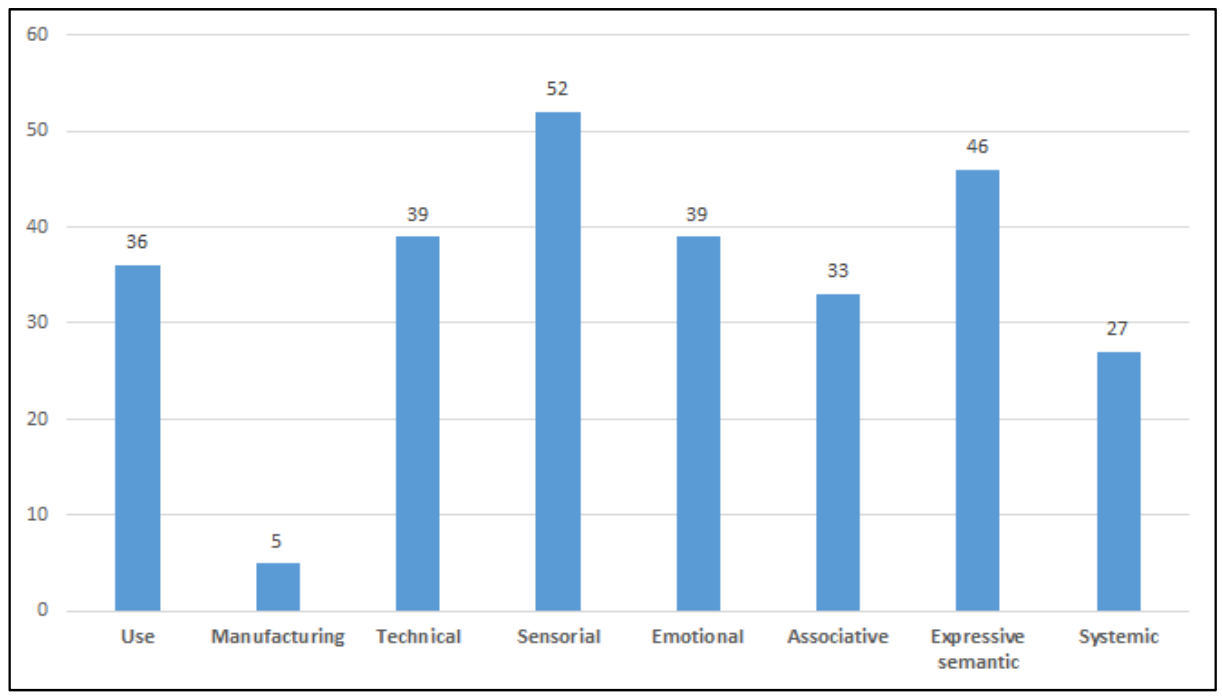

Figure 1. Total frequency of the appraisal categories

Overall, sensorial was found to be the most frequent appraisal theme, followed by expressive semantic and use. Interestingly, there were appraisals that did not belong to any of the existing thematic categories. These were, therefore, framed within a new category called systemic theme. 
The 'systemic' evaluations refer to perceptual analyses of a material within its whole lifecycle including consideration of origin, production, use and end of life. In particular, the analyses provided by users focused on concerns about the materials examined and positive or negative impacts of the materials. Respondents often questioned materials with respect to their origin and end of life. For instance, one respondent wondered why recycled dollar bills were used in the toothbrush: 'Why would you want to recycle dollar bills?' Another respondent argued about the impact of the denim used in the sunglasses: 'How much of the used denim would they actually discard? Because obviously you only take a very little tiny portion of the used denim'. Finally, a participant expressed concerned about the trainers endof-life: '... because usually my trainer last a year or two, and then I will get rid of them... what is going to happen to them then?'

Table 3. Appraisal category and examples

\begin{tabular}{|l|l|}
\hline Appraisal Category & Examples \\
\hline Use description & $\begin{array}{l}\text { For the function of shoe, holes for airflows, hold heavy stuff, } \\
\text { protect stuff, for guys and not for ladies, for active user like } \\
\text { bicycle rider, for ring and necklace, for handle, to stick note, } \\
\text { put food, grasp the handle }\end{array}$ \\
\hline $\begin{array}{l}\text { Manufacturing } \\
\text { process description }\end{array}$ & A layer of coating, set in resin, radius of the edge \\
\hline $\begin{array}{l}\text { Technical } \\
\text { description }\end{array}$ & $\begin{array}{l}\text { Lightweight, dry rapidly, last long, strength, elasticity, } \\
\text { durability, flexibility, water repellent, withstand repetitive } \\
\text { folding movement, stiffness, heat insulation, prevent odour } \\
\text { contamination }\end{array}$ \\
\hline $\begin{array}{l}\text { Sensorial } \\
\text { description }\end{array}$ & $\begin{array}{l}\text { Colour, texture, bumpy surface, scratches, smoothness, } \\
\text { roughness, softness, hardness, odour, sound }\end{array}$ \\
\hline $\begin{array}{l}\text { Emotional } \\
\text { description }\end{array}$ & $\begin{array}{l}\text { Surprise, pleasant, disgust, affection, very relax, feel safe, } \\
\text { anxious }\end{array}$ \\
\hline $\begin{array}{l}\text { Associative } \\
\text { description }\end{array}$ & $\begin{array}{l}\text { Like-vinyl, like-marble, like-plastic, like-fallen leaves, like-paper, } \\
\text { like-leather, like-fake leather, like-cloth }\end{array}$ \\
\hline $\begin{array}{l}\text { Expressive } \\
\text { semantic } \\
\text { description }\end{array}$ & $\begin{array}{l}\text { Luxury, durable, comfortable, beautiful, masculine and rugged, } \\
\text { attractive, original, tough, classic, funny, unique, casual, } \\
\text { warmth, playful, very cheap, nature, simple, straight forward, } \\
\text { unstable }\end{array}$ \\
\hline $\begin{array}{l}\text { Systemic } \\
\text { description }\end{array}$ & $\begin{array}{l}\text { Environmental friendly, organic, biodegradable, eco-friendly, } \\
\text { corporate social responsibility, natural material, renewable, } \\
\text { organic }\end{array}$ \\
\hline
\end{tabular}

\subsection{Patterns of appraisal}

Data analysis showed that the appraisal themes were considered either concurrently or independently. Those that occurred concurrently were found to take the form of network structures. This finding was judged important and deserving further investigation because networks of appraisal adopted by users are likely to correlate with significance and interest. Hence, an analysis was undertaken to identify the appraisal themes that were considered concurrently and recognise patterns within and across users. Various patterns of material appraisal were identified. Two prominent patterns are described below together with examples from the data set. It is noteworthy that in these examples the appraisal themes are also coded in brackets.

The first pattern involved consideration of the semantic, technical and use appraisal themes. Within this pattern the three themes were expressed in no particular order. Appraisals following this pattern often raised concern on the potential to use the materials examined. This can be attributed to unfamiliarity with the materials or expectations from prior experience. As an example, respondents questioned if the denim sunglasses are practical. For instance, one respondent asked: 'First impression unique, very 
creative (expressive semantic). But the nose area, is it going to absorb sweat (technical)? I am afraid this is going to get wet if I am sweating (use)'. If in this case expressive sematic was linked to the novelty of the material used, in other cases it was related to the perceived technicality of the materials. As an example, respondents questioned whether food put inside the mycelium cooler box could get contaminated and the material could become mouldy. For instance, one respondent stated: '...yeah I think it is insulating (technical) but I don't think it is super durable (expressive semantic)... I'd be worried of actually what would happen if it got wet (technical) and also because it is to contain food (use), I'd be worried about mould I guess (technical)'. In another example respondents questioned the strength of the leaves wallet. For instance, a respondent stated: 'But I'm not sure if it will last long (use). Leaves are fragile (expressive semantic), and the folding line inside makes me worried about the material (use), looks like it is not strong (technical)'.

Some appraisals based on the expressive semantic, technical and use themes also led to positive reactions to the potential to use the materials. As an example, respondents were confident that the tarpaulin bag was durable. This can be attributed to the material origin being recognisable or to respondents being able to relate themselves to the technical properties of the materials. For instance, one respondent stated: 'I think this is very strong (technical) and robust (expressive semantic). I think it can hold a lot of heavy stuff (use). It's very functional (use)'.

The second pattern of appraisal involved consideration of the expressive semantic and use themes. The two appraisal themes did not always appear in the same order. Appraisals underpinned by this pattern typically led to positive reactions to the products evaluated. This can be attributed to the perceived usefulness of the material origin as well as to additional benefits. Focusing on the semantic theme, three types of meaning were identified. First, users found meaning in the function that (Wilkes et al., 2016) the material had prior to be embodied in the product assessed. For instance, in the case of the mycelium cooler box, respondents associated the function to contain food with the organic nature of mycelium. A respondent clearly said: 'I think it should be fine (use), it's from mushroom, food related (expressive semantic)'. Second, users found meaning in the fact that the materials bring additional benefits such as personalisation and sustainability awareness. For instance, one of the respondents to the evaluation of the tarpaulin bag stated: '... if you use recycled material (use), it's really hard to make another bag which is the same to this one, the added value is to have a personalised item (expressive semantic)'. Third, abstract meaning and metaphors were also attributed to the products examined. For instance, in the case of the leaves wallet, one of the respondents reconsidered the value of money and nature stating: 'This puts some price to the nature...something where you usually store your valuable is something made by nature that reminds you of nature (expressive semantic). Again, what's the most valuable thing between the two (use), the real money or the nature itself'. In the case of the dollar bills toothbrush several respondents felt that the toothbrush is special and high value. One respondent stated: 'I mean the dollars maybe are not used anymore but still these are valuable stuff (expressive sematic), if people know this they can think that oh maybe my body and the act of washing my teeth (use) is money worth or more than the mere money (expressive semantic)'.

Other patterns identified in the data are sensorial-emotional and technical-use. These are not detailed here as they occurred with lower frequency.

\section{Discussion}

The results of this research have shown that the appraisal of sustainable materials involves evaluations which were not encountered in previous work. The classification of appraisals proposed by Karana (2009) was, therefore, extended to consider a new theme that was termed systemic appraisal. The research demonstrates that the appraisal of sustainable materials compared to that of traditional materials includes systemic evaluations, which regard the broader impact of a material. The elements assessed during systemic evaluations were found to align closely to those characterising the biography of a material as specified by Wilkes et al. (2016).

The dominant themes of appraisal were sensorial and expressive semantic followed by the use, technical, associative, emotional and systemic themes. This result shows that the sensorial and interpretative levels of appraisal are central to the assessment. In particular, with respect to the interpretative experiential level, users sought meaning from systemic, semantic, technical, use, associative and sensorial aspects 
of the materials. The manufacturing theme was found to be low compared to the other themes. A reason for this is that it is typically difficult for users to appraise aspects of the production process of a material and this is in line with the findings from previous studies (Karana and Hekkert, 2009).

At times, the themes of appraisals were found to be elicited in network structures. This result motivated the investigation of these networks to identify patterns within and across the participants to the research. Patterns of appraisal that were found to play an important role in building up perception towards the materials studied are expressive semantic-technical-use and expressive semantic-use. In these networks of appraisal it is typically possible to identify if the evaluation of a theme is positive or negative and understand how it contributes to the evaluation. Overall the results of this research suggest that material appraisal for sustainable materials involves evaluating both single and networked themes and requires making trade-offs between the meaning of the themes and the themes themselves.

The systemic theme of appraisal may help designers or sustainable material manufacturers shape positive sustainable material perception, particularly when a new sustainable material is to be introduced or when a material origin is to be communicated via textual and visual cues. For example, manipulation of material aesthetic is highly essential to give cues about material reliability and help retain the natural look of the material. It can also be used to strengthen the systemic appraisal of the material. The ocean plastic trainer, for example, could have product attributes that signify the ocean or sea and therefore help strengthen users' pro-social value of sustainability.

The expressive semantic theme of appraisal, especially when related to systemic issues, can also be used by designers to propose an interesting material narrative. The narrative may consist of explicit information on origin and proximity of material resources.

\section{Limitations and further research}

This exploratory study has shed initial light on user perception towards sustainable materials. A larger data set of materials and respondents is necessary to develop a deeper understanding of how sustainable materials are appraised. Further research is also needed to systematically examine the conditions under which the value of the 'systemic' theme may change. Focusing on the sensorial properties of sustainable materials can potentially be a rather effective strategy to promote sustainable material consumption as it activates hedonic value.

\section{Conclusions}

A lack of understanding of how sustainable materials are appraised is likely to prevent designers from finding ways to shape positive perception of these materials. This research has examined how sustainable materials are appraised using 'think-aloud-interview' sessions with ten users who were exposed to six material stimuli. First, we have found that by knowing the material origin, users were concerned about the overall impact of the materials assessed. We have framed this evaluation under the 'systemic' theme of appraisal, which refers to the lifecycle of the material from resource to end-of-life. Second, two dominant networked appraisals were identified which are 'expressive semantic-technicaluse' and 'expressive semantic-use'. In the first appraisal network, the material origin has often brought uncertainty to the ascribed meaning due to unknowns about the performance of the materials. In the second network, the function of the material, additional benefits and metaphorical meanings were derived from the material origin. This research also indicates that sustainable material perceptions can be valorised by explicit communication of the uniqueness of the material used.

\section{Acknowledgement}

The authors would like to acknowledge the support for this research from the Slab/Slai Scholarship of the Ministry of Higher Education Malaysia and the Dyson School of Design Engineering.

\section{References}

Ashby, M. and Johnson, K. (2003), “The art of materials selection”, Materials Today, Vol. 6 No. 12, pp. 24-35. https://doi.org/10.1016/S1369-7021(03)01223-9

Bahrudin, F.I., Aurisicchio, M. and Baxter, W.L. (2016), "Sustainable materials in design projects", International Conference 2017 of the Design Research Society Special Interest Group on Experiential Knowledge (EKSIG). 
Biswas, A., Licata, J.W., McKee, D., Pullig, C. and Daughtridge, C. (2000), "The recycling cycle: an empirical examination of consumer waste recycling and recycling shopping behaviors", Journal of Public Policy \& Marketing, Vol. 19 No. 1, pp. 93-105. https://doi.org/10.1509/jppm.19.1.93.16950

Bongard-blanchy, K. and Bouchard, C. (2015), "Dimensions of User Experience - from the Product Design Perspective", Journal D'interaction Personne-Système, Vol. 3 No. 1.

Carlos, J., Nicolás, O. and Aurisicchio, M. (2011), “A Scenario of User Experience”, Proceedings of ICED’11/ the 18th International Conference on Engineering Design, Copenhagen, Denmark, August 15-18, 2011, pp. $182-193$.

Charters, E. (2003), "The use of think-aloud methods in qualitative research an introduction to think-aloud methods", Brock Education Journal, Vol. 12 No. 2, pp. 68-82. https://doi.org/10.1080/02602938.2010.496532

Cleminshaw, D. (1989), Design in Plastics, 1st ed., Rockport Pub, Massachussetts.

Crabbe, A. (2012), "Three Strategies for Sustainable Design in the Developing World", Design Issues, Vol. 28 No. 2, pp. 6-15. https://doi.org/10.1162/DESI_a_00139

Fiksel, J. (2006), “A framework for sustainable materials management”, JOM, Vol. 58 No. 8, pp. 15-22.

Fleming, R.W., Wiebel, C. and Gegenfurtner, K. (2013), "Perceptual qualities and material classes", Journal of Vision, Vol. 13 No. 8, pp. 9. https://doi.org/10.1167/13.8.9

Fujisaki, W., Tokita, M. and Kariya, K. (2015), "Perception of the material properties of wood based on vision, audition, and touch", Vision Research, Vol. 109 No. B, pp. 185-200. https://doi.org/10.1016/j.visres.2014.11.020

Giaccardi, E. and Karana, E. (2015), "Foundations of Materials Experience", Proceedings of the 33rd Annual ACM Conference on Human Factors in Computing Systems - CHI '15, pp. 2447-2456. https://doi.org/10.1145/2702123.2702337

Ho, L. (2014), The Use of Recyclable Materials in Luxury Consumer Products (unpublished report), London.

Hoek, J., Roling, N. and Holdsworth, D. (2013), "Ethical claims and labelling: An analysis of consumers' beliefs and choice behaviours", Journal of Marketing Management, Vol. 29 No. 7-8, pp. 772-792. https://doi.org/10.1080/0267257X.2012.715430

Hultén, B. (2011), "Sensory marketing: the multi-sensory brand-experience concept", European Business Review, Vol. 23 No. 3, pp. 256-273. https://doi.org/10.1108/09555341111130245

Iwata, T. (2015), "Biodegradable and bio-based polymers: Future prospects of eco-friendly plastics", Angewandte Chemie - International Edition, Vol. 54 No. 11, pp. 3210-3215. https://doi.org/10.1002/anie.201410770

Kainz, U.W. (2016), Consumers' Willingness to Pay for Durable Biobased Plastic Products: Findings from an Experimental Auction, PhD thesis, Technical University of Munich.

Karana, E. (2009), Meanings of Materials, PhD thesis, Delft University of Technology.

Karana, E. and Hekkert, P. (2009), “Assessing Material Properties on Sensorial Scales”, In International Design Engineering Technical Conferences \& Computers and Information in Engineering Conference, California, pp. $1-8$.

Karana, E. and Nijkamp, N. (2014), "Fiberness, reflectiveness and roughness in the characterization of natural and high quality materials", Journal of Cleaner Production, Vol. 68, pp. 252-260. https://doi.org/10.1016/j.jclepro.2014.01.001

Kremer, S., Michailidou, I., Von Saucken, C. and Lindemann, U. (2014), "User experience milestones: Structuring the development of experience products", International Conference of Design, User Experience, and Usability DUXU 2014, pp. 308-318. httpss://doi.org/10.1007/978-3-319-07638-6_30

Kuusela, H. and Paul, P. (2000), "A copmparison of concurrent and retrospective verbal protocol analysis", The American Journal of Psychology, Vol. 113 No. 3, pp. 387-404.

Luchs, M.G., Brower, J. and Chitturi, R. (2012), "Product choice and the importance of aesthetic design given the emotion-laden trade-off between sustainability and functional performance", Journal of Product Innovation Management, Vol. 29 No. 6, pp. 903-916. https://doi.org/10.1111/j.1540-5885.2012.00970.x

Luchs, M.G., Naylor, R.W., Irwin, J.R. and Raghunathan, R. (2010), “The Sustainability Liability: Potential Negative Effects of Ethicality on Product Preference", Journal of Marketing, Vol. 74 No. 5, pp. 18-31. https://doi.org/10.1509/jmkg.74.5.18

Magnier, L., Mugge, R. and Schoormans, J. (2017), "Using proximity in sustainable product design”, Conference Proceedings of the Design Management Academy, Vol. 4.

Manzini, E. (1989), The Material of Invention, MIT Press.

Marchand, A. (2008), Responsible Consumption and Design for Sustainability, Legacy thesis, University of Calgary.

McKenzie-Mohr, D. (2000), "Fostering sustainable behavior through community-based social marketing", The American Psychologist, Vol. 55 No. 5, pp. 531-537. https://doi.org/10.1037/0003-066X.55.5.531

Meikle, J.L. (1997), "Material Doubts: The Consequences of Plastic", Environmental History, Vol. 2 No. 3 , pp. 278-300. https://doi.org/10.2307/3985351 
Mota, C. (2011), "The rise of personal fabrication", Proceedings of the 8th ACM conference on Creativity and cognition, Atlanta, Georgia, USA, ACM, pp. 279-288. https://doi.org/10.1145/2069618.2069665

Mudgal, S., Muehmel, K., Kong, M.A., Labouze, E., Gerstetter, C. et al. (2012), Study on different options for communicating environmental information for products, European Commission - DG Enviroment.

Newport, R. (1997), "Plastics and Design", In: Mossman, S. (Ed.), Early Plastics: perspectives 1850-1950, Leicester University Press, London, pp. 102.

OECD (2010), OECD Global Forum on Environment focusing on Sustainable Materials Management, Mechelen, Belgium.

Pedgley, O. (2014), "Desirable imperfection in product materials", DRS2014 Design Research Society Conference. Sweden.

Petersen, M. and Brockhaus, S. (2017), "Dancing in the dark: Challenges for product developers to improve and communicate product sustainability", Journal of Cleaner Production, Vol. 161, pp. 345-354. https://doi.org/10.1016/j.jclepro.2017.05.127

Rodrigues, C., Hultén, B. and Brito, C. (2011), "Sensorial brand strategies for value co-creation", Journal of Innovative Marketing, Vol. 7 No. 2, pp. 40-47.

Rognoli, V., Bianchini, M., Maffei, S. and Karana, E. (2015), "DIY materials", Materials and Design, Vol. 86, pp. 692-702. https://doi.org/10.1016/j.matdes.2015.07.020

Rognoli, V., Karana, E. and Pedgley, O. (2011), "Natural fibre composites in product design: an investigation into material perception and acceptance", Proceedings of the 2011 Conference on Designing Pleasurable Products and Interfaces - DPPI'11, Milano. https://doi.org/10.1145/2347504.2347543

Rognoli, V., Salvia, G. and Levi, M. (2011), "The aesthetic of interaction with materials for design: the bioplastics' identity", Proceedings of the 2011 Conference on Designing Pleasurable Products and Interfaces - DPPI '11, Milano. https://doi.org/10.1145/2347504.2347540

Scherer, C., Emberger-klein, A. and Menrad, K. (2017), "Biogenic product alternatives for children : Consumer preferences for a set of sand toys made of bio-based plastic", Sustainable Production and Consumption, Vol. 10, pp. 1-14. https://doi.org/10.1016/j.spc.2016.11.001

Sharfman, M., Ellington, R.T. and Meo, M. (2001), "The Introduction of Postconsumer Recycled Material into TYVEK", Journal of Industrial Ecology, Vol. 5 No. 1, pp. 127-146. https://doi.org/10.1162/108819801753358544

Shashoua, Y. (2008), Conservation of Plastics: Materials Science, Degradation and Preservation, ButterworthHeinemann, Oxford.

Song, S.S. and Zhao, G. (2011), "Psychological and Emotional Reactions To Anatomical Patterns in Wood", Wood Research, Vol. 56 No. 4, pp. 455-466.

Suggit, M. (1997), "Living with Plastics", In: Mossman, S. (Ed.), Early Plastics: perspectives 1850-1950, Leicester University Press, London, pp. 125.

Tonuk, D. (2016), Making Bioplastics: An Investigation of Material-Product Relationships, PhD thesis, Lancaster University.

Tseng Mu, K. (2013), Other person's trash can be another person's treasure, Master thesis, University of Lapland.

Van Weenen, J.C. (1995), “Towards sustainable product development”, Journal of Cleaner Production, Vol. 3 No. 1, pp. 95-100.

Wang, Y. and Hazen, B.T. (2015), "Consumer product knowledge and intention to purchase remanufactured products”, International Journal of Production Economics, Vol. 181 No. B, pp. 1-10. https://doi.org/10.1016/j.ijpe.2015.08.031

WCED (1987), Our Common Future - Brundtland Report, Oxford University Press, Oxford.

Wilkes, S. (2014), In search of sustainable materials: negotiating materiality and morality in the UK materials industry, $\mathrm{PhD}$ thesis, University College London.

Wilkes, S., Wongsriruksa, S., Howes, P., Gamester, R., Witchel, H. et al. (2016), "Design tools for interdisciplinary translation of material experiences", Materials and Design, Vol. 90, pp. 1228-1237. https://doi.org/10.1016/j.matdes.2015.04.013

Yue, C., Hall, C.R., Behe, B.K., Campbell, B.L., Dennis, J.H. and Lopez, R.G. (2010), “Are Consumers Willing to Pay More for Biodegradable Containers Than for Plastic Ones? Evidence from Hypothetical Conjoint Analysis and Nonhypothetical Experimental Auctions", Journal of Agricultural and Applied Economics, Vol. 42 No. 4, pp. 757-772.

Fadzli Irwan Bahrudin, PhD student

Imperial College London, Dyson School of Design Engineering

10, Prince's Garden, Kensington, SW7 1NA London, United Kingdom

Email: f.bin-bahrudin15@imperial.ac.uk 